\title{
Turbocompound technology on hybrid power trains: urban buses take inspiration from $F 1$ power units
}

\author{
J. Dellacha ${ }^{1}$, M. Repetto ${ }^{2}$, M. Passalacqua ${ }^{2}$, D. Lanzarotto ${ }^{2}$ \\ \& A. Pini Prato ${ }^{2,3}$ \\ ${ }^{1}$ Green Venture, Italy \\ ${ }^{2}$ Genoa University, Italy \\ ${ }^{3}$ N.C.N., Italy
}

\begin{abstract}
The huge boom in the automotive industry, as well as increasing attention for energy saving and reduction of pollutant emissions, has prompted research on developing new propulsion systems. This paper aims to highlight the results obtained by studying a hybrid propulsion system based on turbocompound technology. As the vehicle powertrain has never been changed in the past, and attention was always oriented to the single component, it is now possible to realize new powertrain architecture and to define power flow control algorithms thanks to the introduction of electro-technologies.

By means of this analytical approach, that sees the matching motor-vehicle from a holistic point of view, it's possible to design the components of the propulsion system, in order to maximize the average effective efficiency of the global powertrain. Firstly, the motorsport system adopted by the F1 cars is analysed. Secondly an evaluation of the energy saving achievable in the heavy transport is shown (12 $\mathrm{m}$ urban buses) applying this kind of technology. Ultimately, in order to quantify further improvements, the traditional storage systems (lead-acid batteries), have been replaced by lithium-ion batteries and supercapacitors.

The entire study has been conducted thanks to the development of different mathematical models, implemented on the dynamic simulation tool MATLAB/ Simulink. Many simulations compare the conventional powertrain with the hybrid parallel and series architecture, others compare the performances of different storage systems. The results show the significant potentialities of the hybrid series
\end{abstract}


structure (versus the parallel structure) if applied to urban buses: in addition, the series hybrid bus could halve consumption and take the overall efficiency of the powertrain to $18 \%$ versus $8 \%$ of a conventional bus, thanks to the use of turbocompounds. The turbocompound contribution to the energy saving (4-6\%) is compliant with the bibliography.

Besides, the study shows that further improvements can easily be achieved, both from the charge/discharge efficiency rate standpoint, and from the power flow intensity absorption, by replacing traditional storage systems with supercapacitors.

Keywords: turbocompound, hybrid buses, battery, supercapacitor, energy efficiency.

\section{Introduction}

The recently growing tendency to properly address both environmental and energy savings issues, has increasingly developed the role of hybrid technology in the automotive industry.

The main aim of a hybrid vehicle is to recover the energy derived from braking phases, by matching the internal-combustion engine with one or more electric machines and an extra storage system. In addition, the introduction of the electric components, allows the raising of the efficiency of the entire power train, and at the same time, the improvement of the engine working conditions.

Both the power coming from braking, and the power within exhaust gases is lost in conventional vehicles; while the former is partially or fully recovered in current hybrid vehicles, the latter remains not exploited yet. More precisely, this is correct but for car racing, such as Formula 1. As a matter of fact, enthalpy in the exhaust gases, is partially recovered by the "turbocompound system".

\section{Hybrid conventional architecture}

Two main fundamental hybrid structures have been developed until now.

\subsection{Parallel architecture}

The term "parallel" comes from the mechanical coupling of both the engine and the electric motor to the shaft. A clutch is placed between the ICE and the shaft in order to de-couple the engine from the shaft itself when ICE power is not required, as to prevent high idle losses.

Thanks to this structure, regenerative braking plays a fundamental role as far as energy saving is concerned. As a matter of fact, it can partially replace the engine during propulsion phases by exploiting the energy recovered and stored in the battery.

\subsection{Series architecture}

The term comes from the energy chain organization; the coupling of the engine with an electric motor allows the engine itself not to be mechanically linked to the 
wheel shaft. Thanks to this structure, not only is regenerative braking possible, but it offers a further degree of freedom as regards the choice of engine working point. Indeed, the traction, by being purely electrical, allows the internal combustion engine to work in particular velocity and torque conditions that maximize the thermodynamic transformation efficiency.

Ultimately, a hybrid power train offers potential energy benefits compared to conventional vehicles. The parallel hybrid allows full or partial recovery of the energy derived from braking, and prevents the engine from working in the low and zero efficiency areas. The series hybrid offers all the benefits of the parallel structure, besides, it allows the engine to work around the maximum efficiency point.

\section{Turbocompound technology}

The turbocompound technology can be considered as the current turbocharger evolution. The turbocharger exploits the enthalpy in the exhaust gases to compress the input air to the engine. The extractable energy from exhaust gases, is higher than the quantity needed to compress the feeder air, this energy excess is not yet exploited today. The turbocompound system, uses this surplus to generate useful energy. The first solution envisaged the mechanical coupling of a second low pressure turbine (placed after the turbine linked to the turbocharger) with the wheel shaft through a series of gears and a hydrodynamic joint, because of the large differences in rotational velocity. This structure was too complex and highly dissipative. Thanks to the development of hybrid technology and all the electric components on board the turbine can now be coupled with an electric generator obtaining two main advantages: the elimination of the above mentioned additional gears and the hydrodynamic joint, secondly a great reduction of the "turbo lag" making the turbocharger accelerate by the electric machine in the rapid power transients.

In spite of all the different structures, the energy optimization logic and the overall efficiency, still remains unchanged.

The enthalpy in the exhaust gases reaches meaningful values, only if the engine is close to the full loading condition, this is the reason why turbo compound systems have not developed among conventional vehicles, where the thermal machine working conditions are typically characterized by quick power transients, resulting in a low average of loading.

This system shows remarkable energy potentialities if implemented on a hybrid structure purposefully designed to load the engine [1].

Since 2014, the turbocompound technology has been adopted by F1 racing cars; before that the sport competition in the automotive sector was focused on the optimization of the aerodynamics, while the ICE performances were all aligned due to regulations. Thanks to the introduction of new regulations, quantity of fuel being limited, the focus has been shifted towards the power unit and more precisely to its efficiency. In this perspective, the need to study energy efficient systems has increased, among them, the turbocompound technology has stood out and has shown its validity on applications where engine full loading is required. 


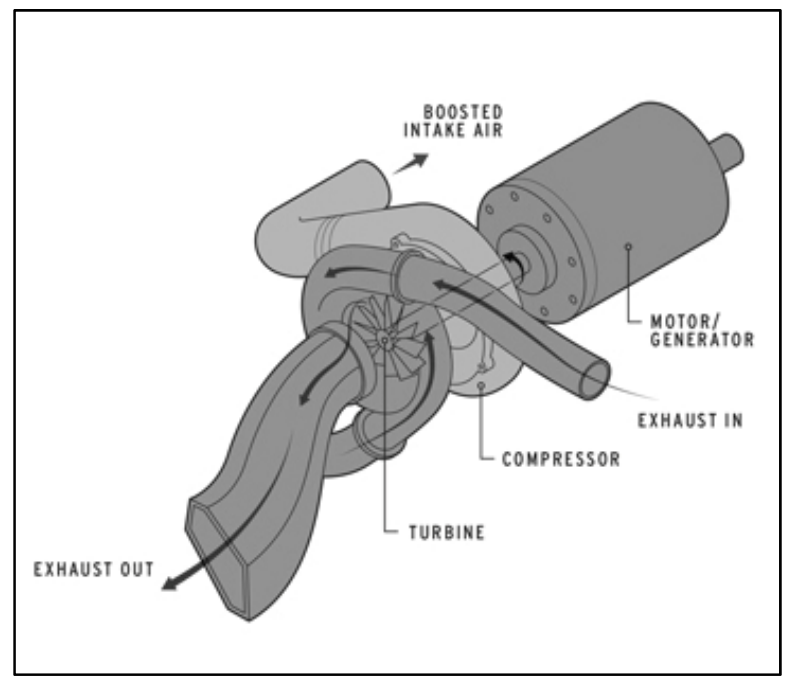

Figure 1: Turbocompound system.

Since 2011, we have been simulating F1 powertrain using a simulation software called "R.A.C.E.". After the new regulations announcement, we have been simulating the new configurations obtaining very similar results to the ones later obtained in the real races. Thanks to the new configurations, the recent F1 championships have shown a 30\% fuel saving rate, and then an increase of the overall efficiency around the same rate. In particular, the most fuel consuming track for instance, the Spa-Francorchamps circuit, has shown a decrease in consumption from $160 \mathrm{~kg}$ to $100 \mathrm{~kg}$.

On the basis of the real data and the ones obtained from simulations, we wondered which commercial application thanks to the introduction of the same technology, would allow us to achieve similar outcomes.

From an energy standpoint, the traditional urban bus, is the most similar class of vehicle to racing cars. The strongest similarity is simply based on the frequent and repeating succession of acceleration and hard braking, furthermore, this similarity includes the high power levels which are required to sustain these phases. As for racing cars, high power comes from high speed, for urban buses, high power is related to large masses. Ultimately, both mission types are characterized by high levels of conservative power, this fact allows great freedom of action towards the efficiency improvement.

\section{Hybrid series powertrain potentialities}

Nowadays, parallel architecture is widespread in the automotive industry, while it is not the same for the series architecture which remains confined to niche applications. 
The above inequality is due to the wider flexibility offered by the parallel structure, by the significant absence of working condition limitations and in the end by an undersizing of the electrical components.

The series architecture is generally characterized by the presence of an undersized engine compared to the traction motor, therefore it cannot carry out road missions (tracks, routes, ways, travels, missions?) where high average power is required (high speed roads, mountain routes). In any case, these limitations can be partially overcome by conveniently acting on the sizing of the electrical components (in particular on the storage system), and on the control logics. An analysis in terms of additional weights, additional costs, an increased structure complexity, and the relations between energy and performance advantages theoretically achievable, is of primary importance: very few data are available so far because no manufacturer has started a chain series architecture based production.

No mechanical constraints link the generation machine to the traction machine, indeed the instantaneous power difference associated with the "independent" dynamics of the generation and the road mission, is supplied by the storage system.

One further improvement in the system efficiency would be possible to achieve by increasing the generation efficiency. This is feasible thanks to the abovementioned decoupling between wheels and generation, thus it allows the engine to provide the vehicle with the average power with no need to follow the low and high power peaks typical of road dynamics. This particular working condition allows the undersizing of the thermal machine down to the level of the average power (considerably lower than the maximum instantaneous power). In addition, the undersizing operation allows the engine full loading, thus exploiting all the efficiency advantages deriving from it.

All these basic considerations account for the turbocompound integration in this system.

\section{Storage systems}

The central role played by the storage system makes it the most critical component, effectively its performances directly affect the global power train efficiency.

The charge/discharge rate efficiency and the maximum power limit are the main parameters of the storage system which have to be accounted for to design control logics for the power flow management.

A large variety of different technologies are available on the market, three storage system types are compared in this study: lead-acid battery, lithium-ion battery and supercapacitor.

\subsection{Batteries}

Batteries represent the conventional storage system used in the automotive industry, depending on the technology, they have very different power limitations efficiency rates, costs and physical/energy properties, but what equates them is the dependence of the charge/discharge efficiency rate on the power intensity. It is 
usually defined a useful parameter " $C$ ", the above-mentioned dependency (efficiency/power) can be linked to this parameter (the efficiency decreases with C). It is also practical to visualize the power working conditions of the battery.

$$
c=\frac{\operatorname{power}[\mathrm{kW}]}{\text { battery capacity }[\mathrm{kWh}]}
$$

Lead-acid batteries certainly represent the most mature storage system technology and the cheapest; its drawbacks are given by the low efficiency rate and the low values of specific power and specific energy.

On the other hand, lithium ion batteries are considered the most performing electrochemical storage system today [2-4].

\subsection{Supercapacitors}

Supercapacitors are ideal components to cycle energy with high dynamics, in the sense that they can be repetitively stressed by fast charge and discharge cycles, despite handling high currents without being damaged.

Specific energy values are very low compared to batteries, on the contrary specific power values are substantial; this fact combined with high speed charge/discharge and long cycle life make them suitable wherever considerable power has to be both recovered and supplied shortly (second fractions to tenths of seconds). Furthermore, this process is characterized by great efficiency rates, indeed the equivalent series resistance (ESR), per cell, is much lower than the batteries ESR. Lastly, the supercapacitor price is comparable to Li-ion batteries, but the latter is stationary now (it is essentially due to the material), the former is still associated with the production process and is destined to fall after hypothetical mass production [8-10].

Table 1: $\quad$ Storage systems comparison: main features.

\begin{tabular}{|c|c|c|c|}
\hline & $\begin{array}{c}\text { Lead-acid } \\
\text { batteries }\end{array}$ & Li-ion batteries & Supercapacitors \\
\hline Specific energy [Wh/kg] & $30-40$ & $60-120$ & 7 \\
\hline Specific power [W/kg] & 150 & $1000-1500$ & 7500 \\
\hline Efficiency [\%] & $60-75^{*}$ & $80-90^{*}$ & $97-99^{* *}$ \\
\hline Specific cost [€/kWh] & 150 & 900 & 4000 \\
\hline Specific cost[€/kW] & 35 & 65 & 3 \\
\hline $\begin{array}{c}\text { Specific cost per cycle } \\
{[€ /(\mathrm{kWh} \text { cycle)] }}\end{array}$ & 0.3 & 0.6 & 0.004 \\
\hline
\end{tabular}

*The charge/discharge value is intended, the first number is associated with automotive applications (high $\mathrm{C}$ values), while the second is referred to the maximum theoretical value. **The charge/discharge efficiency rate is intended, it is a valid range for automotive applications, where maximum power is at most $10 \%$ of the modules' rated power. 


\section{Simulation tool and models}

In order to evaluate the benefits obtainable from the different hybrid solutions, a large number of simulations have been conducted through the MATLAB/Simulink software. A modular model (V.E.C.T.R.A.) [5-7] has been designed in which each physical macro-component and each control logic, is represented by a single block; thanks to this modularity, numerous configurations and different components can be simulated (i.e. conventional thermal configuration, hybrid parallel, hybrid series) and easily compared to one another. The simulation process is divided into three phases:

1. Files data pre-processing and model inputs generation;

2. Simulation;

3. Results elaboration and data analysis.

Finally, the vehicle model (conventional bus model) was validated on three different ECE type approval obtaining at maximum a 3\% - difference in results, compared to the real fuel consumption data.

\section{Vehicles and road missions}

A substantial simulation campaign was carried out considering different types of vehicles, different cargoes (number of passengers) situations and ultimately, different road missions (rush hour, evening, extra-urban). The most significant results are shown below.

Table 2: $\quad$ Urban bus physical features.

\begin{tabular}{|c|c|}
\hline Conventional vehicle mass (full cargo) & $18000 \mathrm{~kg}$ \\
\hline Hybrid vehicle mass (full cargo) & $19000 \mathrm{~kg}$ \\
\hline Rolling resistance coefficient & 0.007 \\
\hline Aerodynamic penetration coefficient & 0.6 \\
\hline Front vehicle section & $7.5 \mathrm{~m}^{2}$ \\
\hline
\end{tabular}

Table 3: $\quad$ Road mission features (rush hour).

\begin{tabular}{|c|c|}
\hline Average speed & $15 \mathrm{~km} / \mathrm{h}$ \\
\hline Maximum speed & $50 \mathrm{~km} / \mathrm{h}$ \\
\hline Maximum height variation & $33 \mathrm{~m}$ \\
\hline Route length & $13 \mathrm{~km}$ \\
\hline Stop and go & 60 \\
\hline
\end{tabular}

\section{Hybrid architectures: results analysis}

The first comparison was developed between the configurations described above; the following features were taken in consideration: 
Table 4: $\quad$ Engine, motor and l.a. battery sizing.

\begin{tabular}{|c|c|c|c|}
\hline & Conventional & Hybrid parallel & Hybrid series \\
\hline $\begin{array}{c}\text { Engine rated } \\
\text { power }\end{array}$ & $240 \mathrm{~kW}$ & $162 \mathrm{~kW}(-35 \%)$ & $90 \mathrm{~kW}(-70 \%)$ \\
\hline $\begin{array}{c}\text { Generator rated } \\
\text { power }\end{array}$ & n.a. & $50 \mathrm{~kW}(*)$ & $90 \mathrm{~kW}$ \\
\hline $\begin{array}{c}\text { Motor rated } \\
\text { power }\end{array}$ & n.a. & $50 \mathrm{~kW}(*)$ & $170 \mathrm{~kW}$ \\
\hline $\begin{array}{c}\text { Traction motor } \\
\text { rated torque }\end{array}$ & $1250 \mathrm{Nm}$ & $1000 \mathrm{Nm}+$ & $870 \mathrm{Nm}$ \\
\hline $\begin{array}{c}\text { Storage system } \\
\text { capacity (l.a.) }\end{array}$ & n.a. & $22 \mathrm{kWh}$ & $22 \mathrm{kWh}$ \\
\hline
\end{tabular}

Note: $(*)$ Generator and motor is the same machine.

It is interesting to note that, the traction by being purely electric, makes the oversizing (with respect to the hybrid parallel) of the electric motor necessary. In addition, for the very same reason, the engine can be undersized.

It was also chosen to adopt lead-acid batteries (i.e. the cheapest) in this first set of simulations, in order to highlight the effectiveness of a structure aiming at the optimization of the entire energy logics instead of the single component.

The main results are presented below:

Table 5: Architecture comparison: simulation results.

\begin{tabular}{|c|c|c|c|}
\hline & Conventional & Hybrid parallel & Hybrid series \\
\hline $\begin{array}{c}\text { Engine } \\
\text { efficiency [\%] }\end{array}$ & 28.6 & 27.7 & 39.9 \\
\hline $\begin{array}{c}\text { Fuel } \\
\text { consumption } \\
{[\mathrm{km} / \mathrm{l}]}\end{array}$ & 2.29 & 3.38 & 3.90 \\
\hline $\begin{array}{c}\text { Mechanical } \\
\text { braking losses } \\
{[\mathrm{MJ}]}\end{array}$ & $27.5(13 \%)$ & $7.54(5.4 \%)$ & $4.0(3.3 \%)$ \\
\hline $\begin{array}{c}\text { Battery losses } \\
{[\mathrm{MJ}]}\end{array}$ & n.a. & $6.3(4.5 \%)$ & $9.0(7.5 \%)$ \\
\hline
\end{tabular}

Note: The percentage rate of energy loss referred to the primary energy needed for that specific configuration, is shown in brackets.

The substantial increase in generation efficiency, despite a greater power flow through the battery (with all its additional losses) has revealed the series architecture to be the most efficient thanks to a fuel consumption reduction reaching $41 \%$ of the original consumption of a conventional thermal vehicle.

As previously described, the mechanical decoupling allows the engine to operate in a small area around the maximum efficiency point equal to $42 \%$. This 
small area is also associated with a high loading rate. It is thus immediate to proceed by inserting the turbocompound system.

Finally, not only is the "pure" series architecture applied to urban buses more convenient (from the efficiency standpoint) than the parallel architecture, but it also makes way for further improvements. This would not be possible in parallel architectures instead, where the torque engine has to instantaneously satisfy what is required by the road mission.

\section{Turbocompound introduction: results analysis}

Simulating the hybrid series with the addition of the turbocompound system was the second step. As expected, a further improvement in the generation efficiency was achieved, therefore reaching $45 \%$ has enabled the system to reduce the fuel consumption up to $11 \%$ compared to the previous series solution.

Table 6: Turbocompound introduction: simulation results.

\begin{tabular}{|c|c|c|}
\hline & Hybrid series & TC Hybrid series \\
\hline Engine efficiency [\%] & 39.9 & 44.7 \\
\hline Consumption [km/1] & 3.90 & 4.37 \\
\hline $\begin{array}{c}\text { Mechanical braking } \\
\text { losses [MJ] }\end{array}$ & $4.0(3.3 \%)$ & $4.0(3.7 \%)$ \\
\hline Battery losses [MJ] & $9.0(7.5 \%)$ & $9.0(8.4 \%)$ \\
\hline
\end{tabular}

Note: The numbers in brackets have the same meaning as the ones in table 5.

\section{Storage system: results analysis}

The previous results have shown the relevant improvement of the energy chain efficiency. This has been obtained by optimizing the management logics of the power flows without optimizing the storage system typology.

The battery firstly adopted is indeed the cheapest but also the least efficient; this kind of battery, on one hand is responsible for $8 \%$ loss of primary energy, on the other hand, another $4 \%$ of the primary energy has to be dissipated on mechanical brakes due to the battery low rate of specific power.

Thus, because of its great influence on global efficiency, other two storage system types were considered: li-ion batteries and supercapacitors.

Table 7: Physical and energy features of the modules adopted in simulations.

\begin{tabular}{|c|c|c|c|}
\hline & Lead-acid & Lithium-ion & Supercapacitor \\
\hline Mass $[\mathrm{kg}]$ & 630 & 200 & 300 \\
\hline Energy $[\mathrm{kWh}]$ & 22 & 14 & 2.3 \\
\hline Power $[\mathrm{kW}]$ & 55 & 90 & $>180$ \\
\hline Price $[€]$ & 3500 & 12000 & 10000 \\
\hline
\end{tabular}


The sizing criteria differ from one system to another; as for the lead-acid battery, mass is the sizing criterion (it was chosen not to be excessive in terms of weight), for lithium-ion battery, power is the sizing criterion (it was chosen to recover most of the regenerative braking energy, simulations as a matter of fact, showed that a hypothetical oversizing would bring negligible benefits). Ultimately, energy is the sizing criterion for the supercapacitor module, it is thus clearly oversized in power, so the power limitation is imposed by the DC-DC converter.

The $\mathrm{C}$ limit for the lead acid battery was set to $\mathrm{C}=2.5$ (where $\mathrm{C}=4$ is the rated limitation) in order to allow the battery to operate in continuous conditions. For the same reason the $\mathrm{C}$ limit for the lithium ion battery was set to $\mathrm{C}=6.5$ (where $\mathrm{C}=7$ is the rated limitation to obtain "long life battery") [2-4].

Another set of simulations was carried out, without considering the turbocompound system (the storage system optimization is indeed independent of it).

As for the supercapacitor simulations, the DC-DC converter rated power was set first to $90 \mathrm{~kW}$ (i.e. the same limit given by the battery), and then set to $180 \mathrm{~kW}$ (i.e. the traction motor rated power), for the battery simulations the power limitation is defined by the battery itself, as mentioned above.

The results are shown below.

Table 8: Storage systems comparison: simulation results.

\begin{tabular}{|c|c|c|c|c|}
\hline & Lead-acid & $\begin{array}{c}\text { Lithium- } \\
\text { ion }\end{array}$ & SC (90 kW) & SC (180 kW) \\
\hline $\begin{array}{c}\text { Consumption } \\
{[\mathrm{km} / 1]}\end{array}$ & 3.90 & 4.05 & 4.44 & 4.54 \\
\hline $\begin{array}{c}\text { Mechanical } \\
\text { barking losses [MJ] }\end{array}$ & 4.0 & 1.0 & 1.0 & negligible \\
\hline $\begin{array}{c}\text { Storage system } \\
\text { losses [MJ] }\end{array}$ & 9.0 & 5.6 & negligible & negligible \\
\hline $\begin{array}{c}\text { DC-DC converter } \\
\text { losses [MJ] }\end{array}$ & 1.4 & 1.2 & 1.1 & 1.1 \\
\hline $\begin{array}{c}\text { Storage system } \\
\text { efficiency [\%] }\end{array}$ & 62 & 82 & 99 & 99 \\
\hline $\begin{array}{c}\text { Storage system and } \\
\text { DC-DC converter } \\
\text { efficiency [\%] }\end{array}$ & 58 & 78 & 91 & 91 \\
\hline
\end{tabular}

The supercapacitor module shows a very high efficiency rate because the power flow intensity is mainly around $4 \%$ of the rated power, and the maximum peak does not exceed $8 \%$.

In addition, if the converter sizing is sufficiently appropriate, the supercapacitors can recover all the power peaks whose value is greater than the batteries' limitations. 


\section{Turbocompound and supercapacitor: best technology}

Finally, the series architecture combined with one supercapacitor module and the turbocompound system has was simulated.

It clearly represents the optimum solution from the overall efficiency standpoint; this can be appreciated in the last summing up table.

Table 9: Best practice: simulation results.

\begin{tabular}{|c|c|c|c|}
\hline & Conventional & Hybrid series & $\begin{array}{c}\text { TC supercap } \\
\text { hybrid series }\end{array}$ \\
\hline Consumption [km/1] & 2.29 & 3.90 & 5.09 \\
\hline Engine efficiency [\%] & 28.6 & 39.9 & 39.9 \\
\hline $\begin{array}{c}\text { Mecchanical braking } \\
\text { losses [MJ] }\end{array}$ & 27.5 & 4.0 & negligible \\
\hline
\end{tabular}

It has thus achieved a reduction of consumption up to $55 \%$ compared to the conventional thermal vehicle, and up to $23 \%$ compared to the original series architecture with lead-acid batteries.

\section{Conclusions}

On balance, the simulative analysis conducted has shown how the series architecture applied on urban buses is able to achieve almost (on rush hour full cargo road missions) a $15 \%$ fuel saving compared to parallel architecture. Besides, this structure is ideal to be integrated with a turbocompound system, which allows a further $10 \%$ fuel saving rate.

On the other hand, the optimization of the storage system, i.e. the application of supercapacitors, enables the hybrid series bus (with no turbocompound) to reduce up to $14 \%$ the fuel consumption against the same vehicle with lead-acid batteries.

Ultimately, the most efficient solution, resulting from both thermal, and electrical optimization processes, i.e. the combination of supercapacitors and turbocompound system, integrated in the series architecture, leads to a fuel consumption reduction rate up to $55 \%$ compared to a conventional bus.

\section{References}

[1] J. Dellachà, L. Damiani, M. Repetto, A. Pini Prato, Dynamic Model for the Energetic Optimization of Turbocompound Hybrid Powertrains, Energy Procedia 45 (2014) pp. 1047-1056.

[2] L. Damiani, J. Dellachà, A. Pini Prato, R. Revetria, Simulation Model of a Node for Smart Grid Applications, Equipped with Photovoltaic Panel, Energy Storage and Electric Vehicle, Journal of Technology Innovations in Renewable Energies, 2014, 3, pp. 199-213. 
[3] G. Pede, V. Sglavo, F. Vellucci, C. Villante, ENEA: Ricerca di sistema elettrico: Report su test di ricarica rapida di batterie a litio, Technical report, 2011.

[4] M. Conte, G. Graditi, M.G. Ippolito, E. Riva Sanseverino, E. Telaretti, G. Zizzo, ENEA: Ricerca di sistema elettrico: Analisi e definizione di strategie di gestione e controllo di sistemi di accumulo elettrico per applicazioni in reti di distribuzione attive automatizzate, 2011.

[5] G. Boschetti, M. Repetto, L. Damiani, A. Pini Prato, Simulation model for the analysis of road vehicles global efficiency, Urban Transport 2011 Congress, 6-8 Giugno 2011, Pisa.

[6] L. Damiani, A. Pini Prato, M. Repetto, Improvement of powertrain efficiency through Energy break down analysis, Applied Energy 121 (2014), pp. 252-263.

[7] L. Damiani, J. Dellachà, M. Repetto and A. Pini Prato, Simulative Comparison between Electric and Thermal Powertrains on Different Real Road Missions, Journal of Technology Innovations in Renewable Energy, 2015,4 .

[8] J. Miller, P. Simon: Fundamentals of electrochemical capacitor design and operation, Technical report, 2008.

[9] E. Tironi, L. Piegari, V.Musolino, ENEA: Ricerca di sistema elettrico: accumulo elettrico con supercondensatori nell'industria. Realizzazione di un tool di progettazione per il dimensionamento su base statistiche e validazione sperimentale della modellistica atta a descrivere le performance di tali sistemi di accumulo, Technical report, 2010.

[10] V. Musolino: Supercapacitor storage system: modeling, control strategies, application and sizing criteria, 2011 Phd thesis, Politecnico di Milano. 